\title{
A clinical evaluation of an Erbium:YAG laser for dental cavity preparation
}

\author{
D. J. P. Evans, ${ }^{1}$ S. Matthews, ${ }^{2}$ N. B. Pitts, ${ }^{3}$ C. Longbottom, ${ }^{4}$ and Z. J. Nugent, ${ }^{5}$
}

\begin{abstract}
Objective A randomised controlled trial to determine the acceptability to dentists and patients of cavity preparation with an Erbium:YAG laser as compared with conventional handpieces. Methods Fifteen dentists (9 GDPs, 1 community dentist and 5 hospital dentists) treated 77 patients (age range 3.5-68 years old) who had two matched cavities, in a split mouth, randomised trial. One cavity was prepared conventionally, the other with the laser, with dentist and patient preference determined by questionnaire.

Results In the majority of cases, where dentists expressed a preference, it was for conventional cavity preparation, and this was significant $(P<0.001)$. In more than half of the laser appointments, dentists had to use conventional handpieces to complete the cavity. Principle difficulties reported with the laser were access ( 25 cases) and slow speed of cutting (11 cases). Patients aged $\geq 10$ years who expressed a preference, preferred laser treatment, and this was significant $(P<0.001)$. Patients aged $<10$ years, assessed using a simplified pictorial questionnaire, did not show a significant preference for either technique.
\end{abstract}

Conclusions Dentists preferred conventional handpieces for cavity preparation while patients aged $\geq 10$ years old preferred laser treatment. Patients $<10$ years old did not express a preference.

$\mathrm{D}_{\mathrm{K}}^{\mathrm{e}} \mathrm{dan}$ ental decay is still a major health problem in the United Kingdom, with $89 \%$ of dentate adults having at least one amalgam restoration. ${ }^{1}$ Yet, one half of all dentate adults claim they are irregular attenders at their dentist, and the principal barrier to regular dental care reported by more than half of these 'irregular' attenders is fear of dental treatment. ${ }^{1}$ Several studies have shown that fear of the drill is a principal cause of dental anxiety among both children ${ }^{2-4}$ and adults. ${ }^{5-8}$ Dental lasers, with their promise of cavity preparation free from noise and vibration would, therefore, seem to have an assured future. However, since clinical studies with dental lasers first began in the mid $1980 \mathrm{~s}^{9}$ the challenge has been to find a laser wavelength and delivery system which will allow removal of both dentine and enamel without causing thermal damage to the dental pulp. There is growing evidence that laser systems using an Erbium Yttrium Aluminium Garnet (Erbium:YAG) source might go some way to meet this challenge. ${ }^{10,11}$ However, the acceptability of such laser systems to

${ }^{1}$ Senior Lecturer/Honorary Consultant, ${ }^{3}$ Professor, ${ }^{4}$ Senior Lecturer, Unit of Dental and Oral Health, Dundee Dental Hospital and School, Park Place, Dundee DD1 4HR; ${ }^{2}$ Community Dental Officer, Community Dental

Department, Central Scotland Healthcare NHS Trust, Falkirk and District Royal Infirmary, Major's Loan, Falkirk FK1 5QE; ${ }^{5}$ Statistician, Dental Health Services Research Unit, Dundee Dental Hospital and School, Park Place,

Dundee DD1 4 HR

Correspondence to: D. Evans

email:d.j.p.evans@dundee.ac.uk

REFEREED PAPER

Received 23.04.99; accepted 11.01.00

(C) British Dental Journal 2000; 188: 677-679 both dentists and patients would have to be demonstrated before their widespread use could be recommended, and this is the aim of the present study.

\section{Method}

The study was a randomised controlled trial, using a split mouth design, of cavity preparation with an Erbium:YAG laser compared with conventional dental handpieces. Local medical research ethics committee approval was obtained and the laser, being classified as Class 4, was operated under local rules drawn up by the Local Radiation Protection Advisor.

The Erbium:YAG laser used in the study (KaVo K.E.Y Laser 1242; KaVo, Biberach, Germany) uses fibre-optics to transmit pulsed laser light with a wavelength of $2.94 \mu \mathrm{m}$ from the main body of the machine through a handpiece similar in size and shape to a conventional dental handpiece. The handpiece focuses the beam about $12-15 \mathrm{~mm}$ from the head of the handpiece, and the depth of field for effective tooth ablation is between $10-20 \mathrm{~mm}$. Focusing is aided by a visible red Helium Neon laser beam which is co-axial with the invisible, infrared Erbium:YAG beam. The frequency of the laser pulses and their energy level can be adjusted from a control screen on the main cabinet of the laser, and those used in the study were within the ranges recommended by the manufacturer. Generally a frequency of 2-3 pulses a second was used, with each pulse ablating a clean crater about the size and shape of a pinhead in enamel, accompanied by a soft 'popping' noise. The efficiency of ablation is increased by means of a very fine water spray from the handpiece.

Fifteen dentists were recruited into the trial: nine general dental practitioners (GDPs), one community dentist and five hospital based practitioners. All the dentists received a course of instruction on the use of the laser, and were required to carry out practice exercises on extracted teeth until they were comfortable with the technique. Patients were selected from those attending dental surgeries for routine dental care and who, by current criteria, required interventive treatment of two matching primary carious cavities. The cavities were matched according to tooth type (permanent or primary;

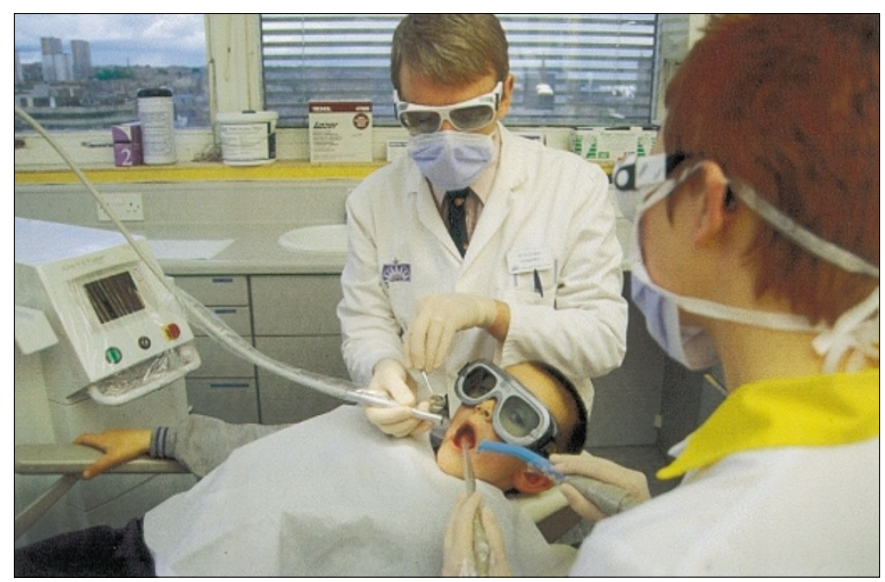

Fig. 1 Cavity preparation with an Erbium:YAG laser 
incisor, premolar etc), cavity type (Black's classification) and cavity depth (less than or more than half way through dentine). Following informed consent, patients had one cavity restored conventionally and one with the laser. To avoid bias, the cavities were completed at two separate appointments, on different days, with the order of methods being determined by opening an opaque sealed envelope containing information randomly generated by computer.

All patients were given the opportunity to have a local anaesthetic if they desired. At the end of each appointment, the patient and dentist completed a questionnaire. At the end of the second visit, patients and dentists indicated which method they would prefer should another filling ever be required. In addition, the dentists were asked to indicate what difficulties, if any, had been experienced with either technique. It was felt that children $<10$ years old were unlikely to be reliable in recalling their feelings about treatment between appointments and so a simplified questionnaire was used. This used diagrammatic representations of four facial expressions, ranging from happy to sad, which the child ticked to indicate how they felt. They were also asked: 'Was there anything you did not like?' and their comments were noted.

\section{Results}

The nine GDPs and the community dentist were asked to recruit between 10-20 patients each and the five hospital practitioners, who had fewer clinical sessions available, were asked to recruit five patients each. Each practitioner had the laser available to them for a continuous period of at least 12 weeks. At the end of the trial, 82 patients (age range 3.5-68 years old) had been recruited; $30(37 \%)$ were $<10$ years old, while $52(63 \%)$ were $\geq 10$ years old. Only four dentists met their targets, while four dentists (three GDPs and one hospital dentist) failed to start any cases at all. Of the 82 cases started, five were not completed. In four cases the second appointment was not kept (two laser and two conventional) while for the fifth case the patient (a 12-year-old boy) refused both conventional and laser treatment. A profile of the completed cases is shown in Table 1.

Each case completed by a dentist is termed a 'dentist/patient encounter' (DPE). The results for preferences for treatment method are shown in Table 2.

Dentists expressed a preference in 73 out of 77 DPE. This preference was for conventional cavity preparation methods rather than the laser, and this was significant $\left(\chi^{2}=26.5\right.$ with Yates' correction; $d f=1 ; P<0.001$ ). To overcome bias in the sample (as not all the

Table 1 Profile of completed cases

\begin{tabular}{|c|c|c|}
\hline & $n$ & $\%$ \\
\hline Total number of cases & 77 & \\
\hline \multicolumn{3}{|l|}{ Dentition } \\
\hline Primary & 18 & 23 \\
\hline Permanent & 59 & 77 \\
\hline \multicolumn{3}{|l|}{ Tooth type } \\
\hline Anterior & 14 & 18 \\
\hline Premolar & 6 & 8 \\
\hline Molar & 57 & 74 \\
\hline \multicolumn{3}{|l|}{ Cavity type } \\
\hline Class I & 41 & 53 \\
\hline Class II & 12 & 16 \\
\hline Class III & 8 & 10 \\
\hline Class V & 12 & 16 \\
\hline Combination & 4 & 5 \\
\hline
\end{tabular}

Table 2 Preferences for treatment method (where a preference was expressed) from 77 DPE

\begin{tabular}{|c|c|c|}
\hline & $n$ & $\begin{array}{c}P \text { value for difference } \\
\text { between groups }\end{array}$ \\
\hline \multicolumn{3}{|l|}{ Dentists preference: } \\
\hline Laser & 14 & $<0.001$ \\
\hline Conventional & 59 & \\
\hline \multicolumn{3}{|l|}{ Patients' preference } \\
\hline (aged $\geq 10$ years old) Laser & 37 & $<0.001$ \\
\hline Conventional & 9 & \\
\hline \multicolumn{3}{|l|}{$\begin{array}{l}\text { Patients preference } \\
\text { (aged < } 10 \text { years old) }\end{array}$} \\
\hline Laser & 5 & ns \\
\hline Conventional & 6 & \\
\hline
\end{tabular}

Table 3 Difficulties that were reported by dentists at least once during their use of the laser from 77 DPE

\begin{tabular}{lccc}
\hline Type of difficulty & $\begin{array}{c}\text { Number of dentists } \\
\text { reporting difficulty at } \\
\text { least once (dentists } n=11 \text { ) }\end{array}$ & $\begin{array}{c}\text { Total DPE in } \\
\text { which difficulty } \\
\text { reported }\end{array}$ & $\%$ \\
\hline Access & 9 & 25 & 33 \\
Slow & 7 & 11 & 14 \\
Focusing & 6 & 10 & 13 \\
Assessing if all caries removed & 5 & 9 & 12 \\
Preparing undercut areas & 5 & 7 & 9 \\
Poor cavity margins & 4 & 6 & 8 \\
Laser breakdown & 4 & 5 & 7 \\
Lack of tactile feedback & 4 & 4 & 5 \\
Assessing depth of cut & 3 & 7 & 9 \\
Noise & 1 & 1 & 1 \\
Smell & 1 & 1 & 1 \\
Too fast with lack of control & 1 & 1 & 1
\end{tabular}

dentists saw the same number of patients), mean preferences for all 11 dentists were determined by scoring their preference for conventional methods as -100 and preference for the laser as +100 for each DPE, and giving each dentist a mean score. This calculation confirmed that the finding that dentists preferred the conventional technique was statistically significant (mean score $=-63.82, \mathrm{SD}=30.22$, $t=7.00, d f=10, P<0.001)$. The difficulties the dentists reported in using the laser are shown in Table 3 and those encountered using conventional cavity preparation techniques in Table 4.

The principal difficulty reported by dentists when using the laser was that of accessing the dental caries. Even on occlusal cavities, access was reported as a difficulty in $39 \%$ of DPE (16 out of 41 ). Specific difficulties identified were the slow speed of the laser, focusing and preparation of undercut areas. One dentist reported spending 10 minutes trying to penetrate occlusal enamel before resorting to the high speed handpiece. With regard to length of appointments, mean times per dentist were compared (to remove bias introduced by different numbers of DPE per dentist), and laser appointment times were shown to be significantly longer $(P<0.001$; Wilcoxon matched- pairs signed ranks test $)$. It was not possible to quantify with any degree of validity how much longer the laser treatments were, since in $52 \%$ of visits ( 40 out of 77 ) assigned for laser treatment, the dentist had to use a conventional handpiece in addition to the laser to complete the cavity preparation. The range and number of difficulties reported by the dentists in their use of the laser (see Table 3) contrast with the very few difficulties that were reported with the conventional technique (see Table 4) although dentists were, of course, relatively unfamiliar with the 'new' laser method. 
Dentists were required to approach the decision as whether to offer local anaesthesia (LA) in the same way on both the conventional and laser visits. In the $62 \mathrm{DPE}$ in which the administration of LA or non-administration of LA at the start of both appointments was the same, dentists reported that there was no significant difference in discomfort between the laser and conventional visits $(P>0.05$; Wilcoxon matched-pairs signed ranks test). However, in more than half the visits scheduled for laser treatment ( 40 out of 77 DPE), dentists had had to use conventional handpieces in addition to the laser in order to complete cavity preparation. Therefore, a valid comparison between laser treatment only and conventional treatment only was not possible with regard to discomfort.

Of the 48 patients aged $\geq 10$ years, 46 patients expressed a preference and in 37 cases this preference was for cavity preparation with the laser $\left(P<0.001 ; \chi^{2}=15.8\right.$ with Yates' correction; $\left.d f=1\right)$. Patients were asked to rate at the time of the laser and conventional visits the degree of pain, vibration, smell, water, time and noise from suction. These data were used to compare the responses of those who had indicated a preference for laser treatment with those who had expressed a preference for conventional treatment, with probabilities being corrected for multiple comparisons (Sidak's multiplicative inequalities correction).$^{12}$ Patients who preferred the laser $(n=37)$ and those who preferred conventional cavity preparation $(n=9)$ both felt that their preferred method was the less painful of the two, and this was significant $(P<0.05)$. Patients who preferred the laser also felt that there was significantly less vibration with the laser $(P<0.05)$, while patients who preferred conventional cavity preparation felt that the laser was significantly slower $(P<0.05)$. The differences for smell, water and suction were not statistically significant for either group.

Twenty eight patients aged $<10$ years completed questionnaires. Their preference for treatment method was determined by comparing their responses to the diagrammatic representations of four facial expressions, ranging from happy to sad, at the end of each appointment. Eleven patients indicated a preference, though this failed to reach statistical significance for either method $(P>0.05$; Wilcoxon matched-pairs signed ranks test). The factors which these patients indicated that they did not like with the two treatment techniques are shown in Table 5.

In more than half of the laser visits no dislikes were expressed and this was also true for more than half of the visits for conventional treatment.

\section{Table 4 Difficulties that were reported by dentists at least once} during their use of the conventional handpieces from 77 DPE (dentists $n=11$ )

\begin{tabular}{ccc}
\hline Type of difficulty & $\begin{array}{c}\text { Number of dentists } \\
\text { reporting difficulty } \\
\text { at least once }\end{array}$ & $\begin{array}{c}\text { Total DPE in } \\
\text { which difficulty } \\
\text { reported }\end{array}$
\end{tabular}

\begin{tabular}{llll} 
Patient discomfort & 3 & 3 & 4 \\
Vibration & 1 & 1 & 1 \\
Removal of all decay & 1 & 1 & 1 \\
\hline
\end{tabular}

\begin{tabular}{|c|c|c|}
\hline Dislike & $\begin{array}{l}\text { Number of } \\
\text { DPE laser }\end{array}$ & $\begin{array}{c}\text { Number of DPE } \\
\text { conventional }\end{array}$ \\
\hline
\end{tabular}

\begin{tabular}{lll} 
Vibration & 0 & 4 \\
Smell & 3 & 0 \\
Soreness & 2 & 3 \\
Noise & 3 & 2 \\
Taste & 3 & 1 \\
Suction & 1 & 1 \\
\hline
\end{tabular}

\section{Discussion}

The results clearly indicate that dentists perceived the Erbium:YAG laser at this stage of its development as offering little advantage over conventional methods of cavity preparation. Four of the 15 dentists failed to start any cases at all, despite receiving full training and support and having the laser available to them for at least 3 months. The principal difficulty reported with the laser was that of gaining access to the caries. Clinicians commented that diffusion of the red Helium:Neon aiming beam on the enamel surface, and pooling of the water spray in fissures made maintaining an accurate focus difficult, which in turn reduced the efficiency of the laser in cutting enamel. Lack of tactile feedback made it difficult to assess when enamel had been penetrated, following which the energy level of the laser has to be immediately reduced to avoid overcutting of dentine. In addition, lasers can only ablate tissue in direct 'line of sight' which caused difficulties in the preparation of undercut areas.

Children younger than 10 years old did not show a significant preference for either method. However, patients more than 10 years old did significantly prefer treatment involving the laser, even though conventional handpieces still had to be used in more than half the cases. Those who preferred the laser perceived it as being less painful and having less vibration than conventional cavity preparation and they seemed to object less than the other group to the longer cavity preparation time. The finding that patients preferred cavity preparation with the laser despite longer treatment times is in agreement with the findings of Keller et al. ${ }^{13}$ However, this study did not report on dentists' preferences. The rapid introduction and universal acceptance of the air turbine handpiece in the 1970s is in sharp contrast to the slow progress in developing a dental hard tissue laser which is acceptable to both patients and dentists. With regard to further development, it is difficult to see how some of the problems identified by dentists in this study (particularly lack of tactile feedback, overcutting of dentine on penetration of enamel and cutting only in 'line of sight') are going to be overcome, although the speed of cutting can be addressed. Until then, the findings of this study indicate that at the current stage of development, Erbium:YAG lasers can, at best, only be considered as an adjunct to conventional handpieces for cavity preparation.

The authors would like to thank Richard Whatley, Richard Collard and Vic Peterson of KaVo (UK) Ltd for their exceptional generosity and support for this study. Professor Pitts and Dr Nugent acknowledge support from the Chief Scientist's Office of the Scottish Office. The views expressed above are those of the authors and not necessarily those of the Scottish Office.

1 Todd J E, Lader D. Adult Dental Health Survey of the United Kingdom 1988. London: HMSO.

2 Cuthbert M I, Melamed B G. A screening device for children at risk for dental fears and management problems. J Dent Child 1982; 49: 432-436.

3 Bedi R, Sutcliffe P, Donnan P T, McConnachie J. The prevalence of dental anxiety in a group of 13- and 14- year old Scottish children. Int J Paed Dent 1992; 2: 17-24.

4 Alvesalo I, Murtomaa H, Milgrom P, Honkanen A, Karjalainen M, Tay K. The Dental Fear Survey Schedule: a study with Finnish children. Int J Paed Dent 1993; 3: 193-198.

5 Gale E N. Fear of the dental situation. J Dent Res 1972; 51: 964-966.

6 Wardle J. Fear of dentistry. Br J Med Psych 1982; 55: 119-126.

7 Scott D S, Hirschman R. Psychological aspects of dental anxiety in adults. J Am Dent Assoc 1982; 104: 27-31.

8 Berggren U, Meynert G. Dental fear and avoidance: cause, symptoms, and consequences. J Am Dent Assoc 1984; 109: 247-251.

9 Melcer J, Chaumette M T, Melcer F et al. Treatment of dental decay by CO2 laser beam: preliminary results. Lasers Surg Med 1984; 4: 311-321.

10 Keller U, Hibst R. Effects of Er:YAG Laser in Caries Treatment: A Clinical Pilot Study. Lasers Surg Med 1997; 20: 32-38.

11 Cozean C, Arcoria C J, Pelagalli J, Lynn Powell G. Dentistry for the 21st Century? Erbium:YAG laser for teeth. J Am Dent Assoc 1997; 128: 1080-1087

12 Rolhf F, Sokal R. Statistical tables 2nd ed. p83 San Francisco: W H Freeman and Company, 1981.

13 Keller U, Hibst R, Geurtsen W et al. Erbium:YAG laser application in caries therapy. Evaluation of patient perception and acceptance. J Dent 1988; 26: 649-656. 